\title{
EDUCACIÓN, MORAL Y CULTURA: TRES FACETAS DEL PENSAMIENTO DE FERNANDO SALMERÓN
}

LEÓN OLIVÉ

\author{
INSTITUTO DE INVESTIGACIONES FLLOSÓFICAS
}

UnIVERSIDAD NACIONAL AUTÓNOMA DE MÉXICO

sabio $[. .$.$] es el que aplica [\ldots]$ enseñanzas sacadas de experiencias vividas [...] Al hombre sabio [...] lo han instruido [...] la observación personal, el trato frecuente con otros hombres, el sufrimiento y la lucha, el contacto con la naturaleza, la vivencia intensa de la cultura [...] Sabio [...] es el que puede distinguir en cada circunstancia lo esencial detrás de las apariencias, el que puede integrar en una unidad concreta las manifestaciones aparentes de un objeto; sabio es también el que, en cada situación individual, puede distinguir mejor lo verdaderamente importante, y para ello tiene una mirada más sagaz que los otros.

No todos pueden acceder a la sabiduría; pocos tienen, en verdad, condiciones para compartirla. Entre la muchedumbre la sabiduría elige a los suyos; a diferencia de la ciencia, ella si "hace acepción de personas". Se niega a los espíritus vulgares, superficiales, llama a los seres sensibles, discretos, profundos.

Luis Villoro

Estas palabras de Luis Villoro, analizando el concepto de sabiduría, ${ }^{1}$ parecería que fueron escritas pensando en Fernando Salmerón. Hombre sabio por excelencia, su vida se caracterizó por la creatividad y la modestia, así como por la coherencia entre su pensamiento y sus acciones: como filósofo de la educación, educador y conductor de instituciones; como filósofo de la moral y hombre íntegro e incorruptible, preocupado por los problemas reales de la sociedad y por lo que la filosofía puede hacer en relación con ellos; como filósofo de la cultura, humanista en el más profundo sentido de la palabra, y pilar de la comunidad de pensamiento iberoamericano.

1 L. Villoro, 1982, pp. 226-227. 
El más destacado filósofo de la educación en Iberoamérica en nuestros tiempos, ${ }^{2}$ un hombre profundamente comprometido con sus convicciones y con sus tareas intelectuales y profesionales, cuando tuvo responsabilidades al frente de instituciones educativas, Salmerón no podía dejar de plasmar sus conocimientos, sus convicciones y su sabiduría, en relación con los problemas de la educación, tanto en el terreno teórico como en el práctico. En su trabajo cotidiano, en sus escritos académicos, y también en sus actos y discursos públicos, encontramos reflexiones profundas acerca de, por ejemplo, el significado, la naturaleza y el papel de las universidades.

Destaca ahí el papel de la universidad como conciencia crítica de la sociedad. Como uno de los crisoles en donde se fragua el proyecto cultural y el proyecto de país que queremos. Dejando claro que ese proyecto, o bien viene impuesto desde fuera, basado en intereses que nos son ajenos, o es un proyecto que se construye desde dentro, forjándose cotidianamente, con base en nuestros intereses auténticos, y en el que entonces la universidad tiene un papel fundamental que desempeñar. La sola decisión de por qué es bueno un desarrollo económico en éste o en aquél sentido, o por qué, para qué y en beneficio de quiénes importa el desarrollo científico y tecnológico, y cuáles son las metas por alcanzar con tales desarrollos, son cuestiones que tiene que decidir la sociedad, si queremos una sociedad de mujeres y de hombres moralmente responsables y verdaderamente libres. Sobre esos problemas la universidad debe ser constantemente creativa e innovadora, y para ello es indispensable el florecimiento de las humanidades.

Pero, en los trabajos de Salmerón, además encontramos reflexiones sobre otros problemas inmediatos, por ejemplo, sobre los desafíos que las universidades enfrentan en distintas circunstancias; la justificación de su autonomía y sus implicaciones morales, educativas, políticas y jurídicas; o bien sobre la problemática relación entre la Universidad, la sociedad civil y el Estado, para mencionar sólo algunos de los temas sobre los que reflexionó públicamente, siempre con rigor y con una argumentación racional, ya se tratara de un escrito académico, ya de una intervención o un discurso público. Por eso hay que agradecer ahora a quienes convencieron a Salmerón de publicar todos esos trabajos —o al menos muchos de ellos-en volúmenes antológicos que hoy todos podemos leer, y así aprender mucho de ellos.

2 "Iberoamérica", en todo este artículo, se refiere al mundo hispanohablante, comprendiendo los países de América Latina y a España. 
En otra faceta de la vida intelectual de Fernando Salmerón y de sus actuaciones públicas, quisiera recordar algunas de sus preocupaciones constantes en los últimos años, que muestran también la coherencia de sus acciones y su pensamiento.

El Premio Nacional de Ciencias y Artes, máximo galardón que otorga el gobierno de México, le fue concedido en el campo de Historia, Ciencias Sociales y Filosofía, en la edición de 1993. La ceremonia de premiación se celebró en "Los pinos", la residencia oficial del Presidente de la República, el 24 de enero de 1994, es decir, apenas unos cuantos días después del levantamiento zapatista en el estado de Chiapas.

Una vez más, Fernando Salmerón no eludió su responsabilidad con la nación. El mismo Gobierno que reconocía la valía de su obra, había intentado durante diez días que conmovieron a la nación y al mundo poner fin al conflicto por la vía militar. Las condiciones mismas del conflicto, la justicia de las causas reivindicadas por los pueblos indígenas y la movilización de la sociedad civil, obligaron a la suspensión de la respuesta militar y a la búsqueda de otras soluciones. Soluciones racionales, pacíficas y sobre todo de largo alcance, que aún están por venir.

En ese contexto, Fernando Salmerón no pudo sino mostrar una vez más la materia de la que estaba hecho. Al entonces presidente Salinas, quien encabezaba el acto, le dijo con claridad meridiana:

de usted [...] esperamos los mexicanos todos, no solamente los miembros de la comunidad académica, el paso de la violencia al diálogo y el logro de una unidad más respetuosa de las etnias y de los campesinos en pobreza extrema, que reoriente los elementos que pueden contribuir a dar cohesión a una sociedad nacional y favorezcan la creación de nuevas relaciones sociales. ${ }^{3}$

Palabras no sólo valientes para pronunciarse en enero de 1994, en "Los pinos", sino palabras sabias. Sabias en su dimensión política, y sabias por el proyecto de nación plural al que apuntan. Única solución real y profunda para la problemática de la diversidad cultural de nuestro país.

Reconocimiento de la diversidad cultural, comprensión de los unos por los otros desde culturas distintas, que aunque tengan diferentes intereses y visiones del mundo, pueden entenderse y cooperar entre sí para desarrollar un novedoso proyecto de nación. En tan delicado terreno, ése fue el pensamiento de Fernando Salmerón, expresado con firmeza en donde debían decirse cosas claras y propositivas.

Salmerón mantuvo esa preocupación hasta el final de sus días. Poco después de la premiación, en julio de 1994, fue invitado a dictar una de

${ }^{3}$ Fernando Salmerón, 1994, p. 5. 
las conferencias plenarias, magistrales, en el Congreso Interamericano de Filosofía, celebrado en esa ocasión en Bogotá, Colombia. El tema de su conferencia fue el de los "Problemas morales de la diversidad cultural". En esa conferencia Salmerón de nuevo desplegó sus virtudes intelectuales: su profundo conocimiento de la historia de la filosofía y la idea de recurrir a ella, no como alarde de erudición, sino para mostrar la pertinencia de las tradiciones filosóficas para aproximarnos a problemas sociales reales, y las cuales, si se aplican de manera innovadora y se les da giros creativos - como lo hizo él- resultan herramientas de oro para la comprensión y resolución de esos problemas de nuestra sociedad contemporánea. Posteriormente, Salmerón desarrolló sus ideas al respecto en su contribución al volumen sobre Cuestiones morales de la Enciclopedia iberoamericana de filosofía (Salmerón, 1996).

En estos trabajos, Salmerón propone una modificación en el aparato conceptual de la tradición que fue siempre su favorita: la kantiana, mediante la incorporación de otro concepto, también ya elaborado por la filosofía occidental desde tiempo atrás, y que en su opinión resulta indispensable para desarrollar el proyecto de nación multicultural por el que abogaba desde su discurso de recepción del Premio Nacional.

Se trata del concepto de "necesidad humana básica", dentro del cual es posible incluir una necesidad que, según nos recordaba Salmerón, había sido ya señalada y defendida de manera importante por el filósofo Johann Gottfried Herder en el siglo xvir: "la necesidad de pertenecer a un grupo particular al que uno se sienta unido, entre otras cosas por la comunidad de lenguaje, de territorio, de costumbres o de recuerdos comunes". 4 Salmerón proponía aceptar esta idea de Herder, manteniendo abierta la línea de inspiración kantiana de la dignidad y de la autonomía, que es inseparable del diálogo y de la argumentación crítica.

Poniendo en juego su propia sensibilidad y creatividad filosófica, Salmerón hace ver que la idea de Herder puede justificarse desde un punto de vista moral en términos de los fines que la ética de Kant reconoce como obligaciones, a saber, la felicidad de los otros.

Las comunidades deberían tener una obligación con respecto a la felicidad de sus miembros, la cual podría lograrse de maneras diversas, de acuerdo con sus planes de vida, y eso requeriría de la participación de todos dentro de la comunidad y debería ser una cuestión de política pública. ${ }^{5}$

Sobre la base de esas ideas, Salmerón propone un modelo según el cual es posible extender el concepto de dignidad a las comunidades, y es posible

4 Fernando Salmerón, 1995, p. 121.

5 Fernando Salmerón, 1996, p. 82. 
reconocer derechos de las comunidades como algo más que sólo derechos jurídicos, pero sin confundir derechos morales y derechos jurídicos, y preservando intacta la esfera de la dignidad personal.

Al proponer este modelo, Salmerón no sólo hace una contribución positiva al debate, sino que además comenta de manera constructiva sugerencias de otros filósofos latinoamericanos que han participado en estas discusiones, contribuyendo con ello a cerrar más el tejido de la comunicación dentro de la comunidad de pensamiento en lengua española, y por otra parte articula una crítica a ciertos puntos de vista que han sido muy influyentes en tiempos recientes a nivel mundial en las discusiones sobre el llamado multiculturalismo.

En efecto, Salmerón desarrolla una cuidadosa crítica al modelo defendido por Charles Taylor en su artículo "Multiculturalism" (Taylor, 1994). Salmerón muestra que Taylor pasó por alto un punto importante de la ética kantiana, precisamente el que a él le permite fundamentar el derecho a la pertenencia a un grupo, desde la perspectiva de la tradición kantiana. La discusión no es por un asunto de erudición histórica, para Salmerón lo que está en juego es la posibilidad de construir hoy en día un modelo que sea adecuado para abordar los problemas de las sociedades contemporáneas multiculturales.

De acuerdo con Salmerón, Taylor rechaza la perspectiva kantiana porque pasó por alto una fina distinción que se encuentra en La fundamentación de la metafísica de las costumbres. Se trata de la distinción entre dos posibles principios de la moralidad, de acuerdo con la cual se oponen "dos fines de la vida de signo positivo, que pueden ponerse en relación con nuestros deberes: 'la propia perfección', y 'la felicidad ajena' ". 6

Es posible proyectar estos dos principios a la esfera pública, pero entonces el ideal de perfección sólo puede pensarse en términos negativos. La propia perfección sólo puede ser un asunto propio, individual y privado. Las comunidades sólo pueden mantener espacios abiertos para la realización de los planes de vida, preservando la dignidad y la autonomía. "Por contraste, el deber de justicia, que consiste en contribuir a la felicidad ajena, es un deber perfecto que nos compete a todos y, más que a nadie, a nuestras organizaciones y poderes". ' Éste es el movimiento clave mediante el cual Salmerón fundamenta dentro de la tradición kantiana el derecho de los individuos a pertenecer a una comunidad, así como las obligaciones de la comunidad frente al individuo.

Al mismo tiempo Salmerón subraya que el concepto de dignidad sólo puede concebirse como un fin negativo: establece los límites que nadie

6 Ibid.

7 Fernando Salmerón, 1996, p. 81. 
puede traspasar, y por consiguiente esos límites son inamovibles incluso frente a derechos del grupo.

Taylor no contempla la posibilidad de incorporar la idea de la necesidad de pertenencia a una comunidad como una necesidad humana básica. Más aún, de acuerdo con Salmerón, de manera equivocada atribuye el origen del punto de vista liberal conservador de que el Estado y las comunidades deberían permanecer neutrales con respecto a las elecciones de los individuos a las ideas de Kant acerca de la dignidad. Y por eso es que Taylor rechazó el modelo kantiano. Pero Taylor no vio ni la fina distinción a la que alude Salmerón, mencionada arriba, ni la concepción de la dignidad como un fin negativo. Si Taylor se hubiera dado cuenta de esto, alega Salmerón; no sólo hubiera tenido que aceptar el modelo kantiano, sino que hubiera visto que la idea de Herder es compatible con el esquema de Kant y hubiera contado con el poderoso aparato conceptual kantiano para fundamentar su teoría moral del multiculturalismo.

Este brevísimo repaso nos muestra el carácter típico del trabajo de Salmerón: el de un filósofo comprometido, que habla y actúa con firmeza en los momentos decisivos, políticamente hablando, pero que además desarrolla creativamente tradiciones filosóficas para ofrecer fundamentos firmes para sus posiciones morales y políticas, no sin dejar de criticar constructivamente posiciones influyentes en todo el mundo, y sin descuidar el tejido y el fortalecimiento de la comunidad filosófica iberoamericana, lo que a final de cuentas es fortalecer la cultura iberoamericana. Pocas obras pueden conjugar todas estas virtudes.

III

La tercera y última faceta de Salmerón que quisiera recordar se refiere precisamente a la estrecha conexión entre sus concepciones acerca de la cultura y su labor personal en la construcción y fortalecimiento de la comunidad de pensamiento en lengua española, lo que equivale a decir, en la preservación y el desarrollo de la cultura iberoamericana.

A propósito de la idea de Herder y la necesidad de la que surge un derecho que Salmerón justifica éticamente, el de pertenecer a una comunidad cuyos miembros comparten las memorias, las tradiciones, la lengua y, sobre todo, un proyecto común, no puede haber lugar a dudas de la profunda identificación que Salmerón sentía con la cultura de la lengua española. Entre otras razones, por eso, a pesar de que muchos de sus trabajos fueron publicados o traducidos a otros idiomas, de manera deliberada - como muchos humanistas iberoamericanos- quiso siempre escribir y publicar principalmente en español, consciente del significado de ello para la preservación y el florecimiento de nuestra cultura. 
"Cultura y lenguaje" es el título y el tema de otra espléndida conferencia de Salmerón, pronunciada en el contexto de un encuentro de filósofos de lengua española de diversos países. (Conferencia magistral de clausura del II Encuentro Hispano-Mexicano de Filosofía Moral y Política; leída en Madrid el 19 de septiembre de 1986.) ${ }^{8}$

En esa conferencia, Salmerón desarrolla una ingeniosa idea capaz de dar cuenta del proyecto común, filosófico, de pensamiento y de cultura, que agrupa a los países de lengua española. Mantiene ahí la distinción entre "filosofía" y "pensamiento" que a Salmerón le gustaba hacer, siguiendo a su maestro José Gaos, entendiendo el pensamiento como un concepto que alcanza "a la filosofía en sentido estricto, pero también a las ideas expuestas con métodos científicos o expresadas en la literatura a propósito de problemas de circunstancias". 9 Además, Salmerón defendió de nuevo y de manera vigorosa ideas que compartió con su maestro, y que gracias en gran medida a los esfuerzos de Salmerón se han ido realizando: mayor comunicación entre las comunidades de pensamiento en los países hispanohablantes, la necesaria atención a nuestras tradiciones culturales y a sus clásicos en materia de historia de las ideas; la necesidad de hacer valer la propia lengua en la comunidad filosófica internacional, toda vez que es esa lengua la que forma parte de la tradición de pensamiento y de la cultura a la que uno pertenece. Además, Salmerón abogaba por algunas cuestiones de orden práctico que habían sido también el sueño de su maestro Gaos, como la realización de un gran congreso que convocara a todos los pensadores del mundo hispanohablante.

En este punto vale la pena señalar que gracias en gran medida a la labor de Salmerón, el proyecto de la Enciclopedia iberoamericana de filosofía lleva ya varios años en marcha, y cuenta con frutos maduros (quince volúmenes publicados hasta la fecha). Y en septiembre de 1998 se llevará a cabo en España el I Congreso Iberoamericano de Filosofía, realizándose así el sueño de Gaos y del propio Salmerón.

Pero volviendo a aquella conferencia, Salmerón decía entre sus conclusiones que:

aquellos que, sin dejar de ser nacionales, no queremos ser nacionalistas; pero que tampoco nos hacemos ilusiones con respecto de los imperios y no esperamos en poco tiempo una vida intelectual planetaria, sentimos bajo los pies la tierra sólida cuando nos afirmamos sobre las culturas nacionales de los paises que comparten las lenguas que han nacido en la península ibérica. ${ }^{10}$

8 Fernando Salmerón, 1988.

9 Ibid., p. 192.

10 Op. cit., p. 203. 
Y luego agregaba una nota: "esto es para nosotros la isla de Rodas". Salmerón aludía a una de las interpretaciones de un adagio griego que venía comentando en la conferencia, y que Hegel menciona en el prefacio de su Filosofía del Derecho. El proverbio griego, que Hegel comenta además en traducción latina (probablemente de Erasmo, como señala Salmerón), traducido al español dice: "Aquí es Rodas y aquí hay que saltar".

Según una primera interpretación, como lo explica Salmerón, el proverbio significa que "cada uno es hijo de su tiempo - y sabe que no puede saltar más allá de este tiempo". ${ }^{11}$ Ése es el sentido en el que Salmerón dice que las culturas nacionales que comparten las lenguas ibéricas son "para nosotros la isla de Rodas". Son la realidad cultural de donde podemos tomar nuestras opciones, y no podemos saltar más allá de esa realidad, en el sentido de que no podemos y no debemos negar nuestra cultura, nuestra tradición, nuestro lenguaje y nuestros problemas, so pena de embarcarnos en puras construcciones de la imaginación.

Pero Salmerón comenta dos interpretaciones más del adagio. La segunda dice que el proverbio se aplicaba a quienes estaban dispuestos a fanfarronear acerca de sus hazañas en lugares lejanos, pero que difícilmente las mostraban en su lugar de origen de manera efectiva.

"Aquí es Rodas, aquí hay que saltar", entonces, es una exigencia de mostrar que uno es capaz de hacer lo que pregona. Salmerón sugiere que, aplicado a la filosofía, el proverbio "trata de una exigencia de objetividad: no basta el convencimiento privado de una opinión - hace falta el control de validez intersubjetiva". ${ }^{12}$ Con esto Salmerón defiende una vez más la exigencia de claridad, de rigor y de argumentación racional que él siempre practicó, desechando la idea de la filosofía como mera opinión, incapaz de sujetarse a pruebas de validez objetiva.

Finalmente, Salmerón comenta una tercera interpretación. Nos explica que la "palabra griega para Rodas puede significar también una rosa; y el verbo saltar en latín vale también como el imperativo de danzar". ${ }^{13}$ Según esta interpretación, el adagio puede traducirse como "Aquí está la rosa, aquí hay que danzar". Y lo que quiere decir es que la tarea del filósofo, que tiene de su lado a la razón, "es encontrar la alegría en la realidad presente que describe: la filosofía puede danzar en este mundo real, sin necesidad de posponer la alegría en una futura construcción imaginaria". ${ }^{14}$

11 Op. cit., p. 202.

12 Ibid.

13 Ibid.

14 Ibid. 
Salmerón propone aplicar el proverbio, así interpretado, a la comunidad filosófica, a la comunidad de pensamiento, y finalmente a la cultura iberoamericana toda, simbolizando la alegría al reconocerse a sí misma, al reconocer su existencia real con su propia identidad, con sus proyectos propios, y como parte del concierto mundial. Por ello, enseñaba Salmerón, no hay que cejar en el empeño de que nuestra comunidad de pensamiento integre su propio diálogo, para participar desde él en el diálogo internacional, dejando atrás toda forma de dominación o subordinación.

Pero también Salmerón, seguramente sin darse cuenta de ello, con esas bellas palabras nos mostraba la esencia de su vida y de su pensamiento, pues él nunca nos contaba sus hazañas en tierras lejanas, sino que siempre mostraba ante nosotros de manera efectiva sus habilidades, sometiéndose invariablemente al control de las pruebas de calidad y de objetividad que se exigirian en cualquier parte del mundo. Pero también sin lugar a dudas Salmerón fue un hijo de su tiempo. Hijo predilecto de la cultura iberoamericana, desarrolló un pensamiento auténtico y original para abordar los problemas reales de nuestra sociedad, y para expander nuestro horizonte cultural. Horizonte moldeado por la herencia ibérica y por las diversas culturas americanas, muchísimas de ellas vivas, que conforman un muy rico mosaico cultural.

El pensamiento de Fernando Salmerón fue, con la razón de su lado, como la danza alegre de la filosofía. $Y$ así fue su vida: alegre, plena y llena de amor a su familia, a sus amigos, a sus colegas, a sus discípulos y a la humanidad toda. Por eso su huella es imborrable, y su figura permanecerá eternamente en nuestra realidad, como su pensamiento, danzando con alegría.

\section{BIBLIOGRAFIA}

Salmerón, Fernando, 1988, "Cultura y lenguaje", en Ensayos filosóficos (Antología), SEP, México, pp. 189-203 (Lecturas Mexicanas, 2a. serie, no. 109).

__, 1994, "La diversidad cultural y el espacio del diálogo" (Discurso pronunciado en la entrega del Premio Nacional de Ciencias y Artes 1993, en la residencia oficial de "Los pinos", 24 de enero de 1994), Boletín de la Academia, Academia de la Investigación Científica, no. 18, mayo-junio de 1994, pp. 4-5.

_- 1995, "Problemas morales de la diversidad cultural", en El trabajo filosófico de hoy en el continente, Memorias del XIII Congreso Interamericano de Filosofía, Carlos B. Gutiérrez (ed.), Sociedad Interamericana de Filosofía-Sociedad Colombiana de Filosofía, Bogotá/Colombia, 1995, pp. 121-130. 
—_, 1996, "Ética y diversidad cultural", en Cuestiones morales, Osvaldo Guariglia (ed.), vol. 12 de la Enciclopedia iberoamericana de filosofía, Ed. Trotta-csic, Madrid, 1996, pp. 67-85.

Taylor, Charles, 1994, "The Politics of Recognition", en Amy Gutmann (ed.), Multiculturalism, Examining the Politics of Recognition, Princeton University Press, Princeton, Nueva Jersey.

Villoro, Luis, 1982, Creer, saber, conocer, Siglo XXI, México. 